\title{
THE INTEGRATIVE APPROACH IN TEACHING STUDENTS WHO WILL BE PRIMARY SCHOOL TEACHERS IN FUTURE
}

\author{
B. Baycheva*, M. Tsankova, Z. Zhekov \\ Konstantin Preslavsky University of Shumen, Bulgaria
}

\begin{abstract}
Getting to know the integrative interactions is an important part of the students training. The awareness of it will help the students to master the necessary knowledge, skills and competencies for their application in the practice at school. The use of the integrative approach will diversify and enrich considerably their work as primary school teachers.

The present paper considers the opportunities for cross curricular education by the use of integrative links between Musics and the subjects from the natural cycle. The students get knowledge about the opportunities to apply Musics in the practice with the school children in formation of knowledge bout the natural and social world. By using the integrative approach the education is realized in unity as a whole, and it is not isolated only within the range of a particular subject.

The purpose is to acquaint the students with the integrative links which appear in the interaction between Musics and other subjects such as Environment, Homeland, People and Nature and the formation of skills for their putting into practice with the primary school students.
\end{abstract}

Keywords: integrative links, education, music, nature.

\section{INTRODUCTION}

Integration processes in science and social practice attracted the attention of the scientific community and adversely affected the style of thinking in different fields. In a globalizing world integration of the various spheres of public life puts stamp on integration in different levels of education (1: 48-49).

Integration processes in education are quite complex and versatile in the type of their event phenomenon (2). Under integration in training some authors understand "subjugating subjects of a basic rational idea, others - subordinating objective content of intellectual skills, third rediscover integration in some subjects and fourth saw it as a necessity for the whole range of subjects" (1:49). "Integration - this is not just merging parts into a whole, and the system that leads to quantitative and qualitative changes at different levels - internal, interdisciplinary and inter-system' (2).

How these processes influence science and education today? What trends are observed

\footnotetext{
* Correspondence to:Bozhanka Baycheva, Konstantin Preslavsky University of Shumen, 9302 Dobrich, Dobrotitsa 12, College - Dobrich, GSM: 0899901934,bbaycheva@abv.bg
}

now and how they influence the education of students and pupils? These issues are the subject of our attention.

Today the question of integrative connections in education is very topical, because these relationships are embodied in the curriculum of subjects taught in primary school. In the NES and music curricula for elementary school are given opportunities for cross-curricular learning with other subjects $(3,4)$. Music performed integrative relationships with native land, surrounding world, man and nature, Bulgarian language and literature, mathematics, English, art and more. Integrative connections play a vital role in the integration processes taking place today in which the role of the teacher is unmistakable. Therefore, students need to be trained to use integrative education in their future work as teachers. The purpose of this training is to achieve qualitatively new knowledge and skills for their application.

In the contemporary world it is important to educate individuals prepared for life. The construction of the individual can not be done unilaterally by teaching a course in one subject. It is therefore necessary to ensure that 
BAYCHEVA B., et al.

acquiring interconnected knowledge through the implementation of intergrative education. The main objective of this training is to give a comprehensive picture of the surrounding world.

\section{Presentation}

This paper discusses the possibilities for interdisciplinary learning through the use of integrative connections between music and the subjects of the natural cycle. Students acquire knowledge about the possibilities of application of music in the practical work with students in the formation of knowledge about the natural and social world. Using integrative approach learning takes place in unity, completely, not only in the isolation of the individual subject.

The aim is to acquaint students with integrative connections that arise in the interaction of music with subjects surrounding world, native land, man and nature, and the formation of skills for application in working with elementary school students.

Regarding the objective students acquire theoretical and methodological integrative connections that arise in the interaction of music with subjects from the natural cycle taught in primary school. They acquire knowledge and skills necessary for the development and implementation of integrated lessons where not only occasionally, but used intentionally links. The aim of inclusive education is to achieve qualitatively new knowledge and skills for their application.

In preparing the students of pedagogical specialties in College Dobrich an integrative approach is realized to train various disciplines. This contributes to the coordination and continuity in teaching, combining knowledge and skills and providing summarized ideas in the studied problems. This leads to consideration of the issues of the aspects of different disciplines and gives an overall picture of them. Familiarization with the problem of integration, integrative connections and application of the integrative approach in the practical work with students is an important part of the students' preparation. The problem of integration is one of the priorities of modern education and contributes to the overall preparation of students - future teachers. An important task is to strengthen the integrative approach to the curriculum and the teaching of subjects to the student teachers. (Figure 1)

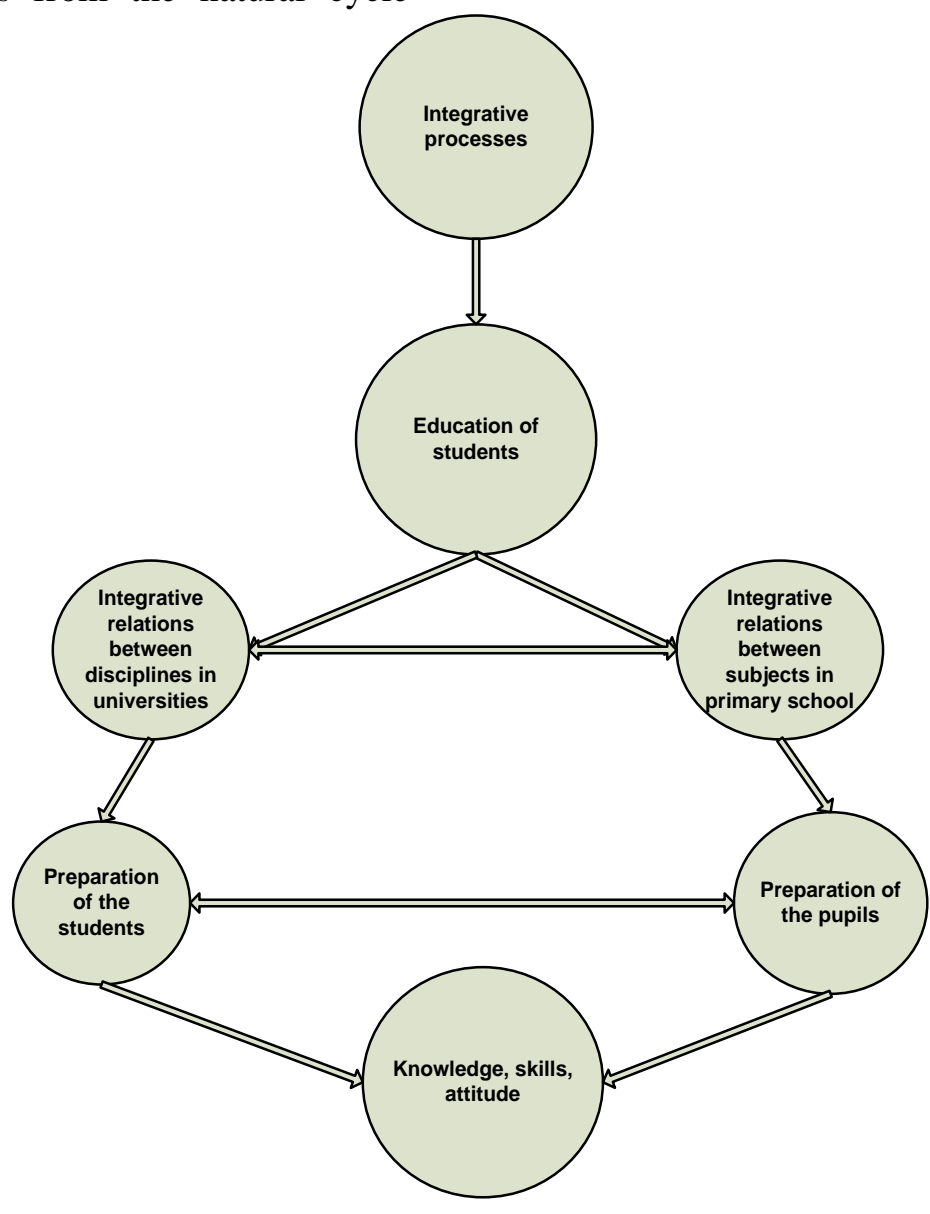

Figure 1 Influence of the integrative processes on the preparation of the trainees 
In the process of learning in higher education are considered integrative connections of music - ambient world. Thus, students acquire knowledge about the possibilities of using music in the practical work with students in the formation of knowledge about the natural and social world. Using integrative approach in the training of students, the teacher has an overall interconnected and learning process in which knowledge in various disciplines is integrated. Topics related to the specifics of music provide opportunities for creating varied integrative links with the educational content of school subjects, giving knowledge about nature. Methodology of teaching natural science students acquire knowledge and skills in the use of music lessons in the end, surrounding world, man and nature with a certain didactic orientation. Student teachers learn how to familiarize their students with representatives of the animal world, seasons, natural phenomena, etc., using a variety of musical tasks. For example, students have the task to compose soundscapes - cuckoo in the forest, autumn picture, winter, spring, wind, rain, storm and others. Thus, by comparing the means of expression of individual objects, they make parallels. And by comparing the two parallel subject knowledge is consolidated and stored permanently.

In elementary school music is used:

> In various forms: lesson, extracurricular activities in elementary school. For example, it is used during lessons, excursions, walks, holidays, celebrations and others.

> In various types of lessons: Lessons for new knowledge, lesson for consolidation and skill formation, lesson for summary and systematization of knowledge, combined lesson.

> In various parts of the lesson: updating old knowledge, stating and motivating theme, exhibition of new knowledge, reinforce the knowledge of the lesson. For example, when updating knowledge for different seasons a variety of music and songs from the repertoire of elementary school may be used. On the basis of the analysis of it the knowledge of the conditions during the season is updated.

$>$ In various content topics: Live nature; inanimate nature; natural phenomena physical, chemical and biological; public and social protection and others.

Educational content of the music in each class is systematically repeated in several major musical themes related to global issues of all the educational content in the primary grades. Thus creating conditions for complex, integrative approach to solving different pedagogical tasks.

Topics related to the specifics of music provide opportunities for creating varied integrative links with educational content around by the world and native land.

Many of the songs in the music books (grades 1-4) are devoted to:

$\checkmark$ Motherland;

$\checkmark$ mom;

$\checkmark$ the family;

$\checkmark$ school;

$\checkmark$ the national holiday of Bulgaria - March 3 ;

$\checkmark$ May 24, the Day of Bulgarian Education and Culture;

$\checkmark \quad$ Bulgarian folk traditions and customs, etc.

Students are introduced to Christmas Eve, Christmas, Basil, Easter (Easter), Baba Marta (1st March), Palm day etc., They learn about the essence of the most popular folk-music examples (Christmas songs and songs connected to other customs and traditions). Acquainted with the purpose and meaning of the studied rituals and customs, their elements and symbolism, connect them with the appropriate holiday.

Students sing songs and listen to music related to the topics above. By so selected musical material in them instill a sense of national pride, of love for the motherland and all native.

$>$ the formation of the different concepts: biological, geographical, historical, ethnographic and others. For example, when introducing students to a variety of plants, they sing or listen to a certain song dedicated to a representative plant (e.g. snowdrop, tulip, crocus, violet). In the lyrics there are presented certain characteristics of the plant - color, shape, parts of the plant and others.

Nature and its inhabitants are an integral part of a child's imagination and a way to explore the world around them. Music in a new way reveales to the children the characteristics of objects and phenomena that they have not noticed in the environment so far. It develops fantasy and imagination, makes them feel joyful feelings, sets them to positive emotions. Under its influence in the children's minds there are created vivid images of fairy tale characters embodying the struggle of good and evil, seen in a new light their surrounding nature, feel its unique beauty. Suggested listening to sound pictures, allow students to 
take a full shape and what happens in nature in the field, in the woods, voices of birds and more. Students complement their knowledge of animals, listening to different music - "The Elephant", "hens and roosters," "The Swan," "Aquarium" and others. music by Camille Saint-Saens, "The Tale of the hen and the fox" - music. Kr. Miletkov "donkey with buggy music. Hadjiev and others.

\section{$>$ the realization of didactic games and in lessons and physical activities:}

In presenting the educational content of natural and social environment in primary school, especially in I and II class used didactic games. They facilitate the adoption of academic information and facilitate activation of cognitive activity. When different types of games are organized, songs are often used. For example, some mobile games using music and their content is related to the knowledge of the outside world. Such games are used in conjunction with the study of plants, animals, relief forms, objects of social environment, etc. folk traditions. Students perform storylines games in which embody the creative images in movement, using elements of dance, mimic movements and others. Recreate characters from the game, highlighting the most characteristic traits and habits. These games can be used to reinforce knowledge, emotional attitude or transition to other activities.

As a result of integrative education students receive more complete, comprehensive, quality new knowledge about the nature of the interaction between man and the environment, employment and lifestyle of the Bulgarians, customs and traditions of ethnic communities.

Familiarizing students with integrative interaction is an important part of their preparation. Absorption will help students master the necessary knowledge, skills and competences for their application in practical work in school.

In modern times it is essential to strengthen education by implementing unity between training and education. This helps create the conditions for conversion of modern society into a society without violence, with relationships, which are based on moral principles. Students - future teachers not only form knowledge of the role and place of man in nature, but also contribute to developing skills for building in the younger generation of ethical approach to nature and to living organisms.

Through connections with nature, positive attitude to it and skills for its protection are developed in children. Touching the living world of plants and animals enriches children emotionally and physically. Practice shows that communication with nature is essential for children who suffer from certain diseases. For example, people with autism, cerebral palsy, neurological disorders, children with speech problems and more. This communion with nature, touching animals can be part of the overall treatment of children and be a complementary treatment. Experience confirms that it both stabilizes the physical and emotional state, improves thinking, speech, the children gain new knowledge and skills. Children communicate "directed and omnidirectional with animals' (5). Omnidirectional, when for whatever reason, they encounter animals - at home, at the zoo, the circus, in nature. Directed - when communicating with animals is used as a therapy for improving health. According to the species of animals used therapy is divided into: "hippotherapy (therapy with horses) canisterapy (therapy with dogs), Dolphin therapy (treatment with dolphins) felinoterapy (treatment with cats), apitherapy (treatment with bee products and bee) Girudotherapy (treatment with medicinal leeches) asinoterapy (whooping therapy). They often use not only animals but also their images. In psychotherapy they also work with sounds issued by animals" (5).

When communicating with objects from nature the emotional state of the children is influenced. This affects their health condition. This places overall impact on the child's body i.e. unity is realized - physical and psychological. In the classes students comment on the meetings with the animals, often with music they play the role of their favorite characters. Often they interpret sounds and behavior. By performing songs students express their thoughts and feelings. Performing songs has a particularly large effect in children with speech problems - they overcome their constriction. Our observations indicate that this way they become stronger and improve their communication skills.

It is good when adults who surround children as teachers, psychologists, parents understand and know these relationships with nature in order to apply them in practice. This will contribute to the enrichment of children and to improvement of their physical and mental health. Knowing the relationships between objects and living children under the supervision of well-trained therapists can stimulate emotional state, mental and physical 
BAYCHEVA B., et al.

development and improve certain existing deviations in healthy aspect. Adapted methods and tools can be applied when working with children with special educational needs.

Application of music lessons on the subjects of the natural cycle in connection with the implementation of training and education function of the lesson:

$>$ With training function using music is related to the perception and understanding of a particular learning content. It is aimed at supporting learning by students and acquisition of knowledge and skills related to the natural and social environment. Music contributes to a motivated, sustained and thorough formation of ideas and concepts of objects and phenomena of the surrounding world. Music in the lessons of the subjects of social and natural environment is subject to and used for the realization of the objectives of the lesson and utilization of educational content. "In addition to the expansion, systematization and generalization of the knowledge, the training function of the lesson is associated with the formation of different groups of skills" (6: 100): cognitive, practical, organizational.

- Music supports the implementation of the educational function of the lesson related to the implementation of educational goals. It aids carrying out tasks related to moral, environmental, aesthetic, intellectual, education and others. The impact of music on pupils appears as an invaluable factor in the aesthetic education in the formation of human personality. Under the influence of music students respond to everything good and beautiful in the outside world, experiencing love for the homeland, friendly feelings towards people of different nationalities. The training process aims at transferring beautiful of communing with nature to the relationships between people.

\section{CONCLUSION}

As a result of the impact and the interpenetration of knowledge gained through interdisciplinary studies, the students obtain a new, full, complete knowledge in which they reach a qualitatively new level of understanding of the course content. By incorporating music in teaching, students gain knowledge in two or more subjects simultaneously in a fun and pleasant atmosphere, which increases their motivation for active work. They receive many ideas on how to use integrative interactions occurring between the subjects taught in primary school.

* The report was made with the support of the "Research" University of Shumen project RD08-276/11.03.2015.

\section{REFERENCES}

1. Andreev, M. Integrative trends in education. NP, S., 1986.

2. Velichko, E.D. and others. Integrative processes in education. http://festival.1september.ru/articles/51719., 20/04/2015.

3. State educational requirements for learning in primary education stage 1-4 grade. https://www.mon.bg/?h=downloadFile\&file $\mathrm{Id}=207$., visited on 15/04/2015.

4. Curricula for primary education stage 1-4 grade.https://www.mon.bg/?go=page\&page $\mathrm{Id}=1 \&$ subpage $\mathrm{Id}=28 ., \quad$ visited $\quad$ on $04 / 15 / 2015$.

5. https://zgalevska.wordpress.com/2013/01/0 5/animal_therapy_for_kids/

6. Mircheva, I., Problems of didactics of homeland studies and natural science, "VEDA speech", S., 1997. 